in finding the extremity of the wire or threaded probe among the clots, which difficulty has suggested the watch-spring instruments of the shops, which is not always at hand, nor, henceforth, need be. Now fasten the hook formed at the extremity of the wire, and which projects anteriorly out of the nose through the mouth, into the projecting loop in the pharynx; and, having drawn it ont of the mouth, include as much lint as will suffice for a plug, securing it simply by twisting. Now retract it above the velum pendulum palati into the posterior nares, till the progress of the plug is arrested; next separate the ends hanging from the anterior nares, place a second plug between them, pressing it up to the noose previously mentioned, and securing this by a common knot, we finish the operation.

The advantages of this instrument are thus obvious-viz., the facility of obtaining its material in the poorest cottage upon an emergency; its projecting into the pharynx quite as well as the watch-spring instrument of the shops, thus rendering the operation almost momentary; its being strong enough to pass as a probe, and sufficiently delicate to tie as a ligature. Further, the way whereby the posterior plug is secured by twisting, enables the operator to increase the size of the plug instantly, should it be fonnd too small, and accidentally be drawn through anterior nares, which accident, were the plug secured by a knotted thread, would complicate the old, troublesome, and sometimes tedious operation.

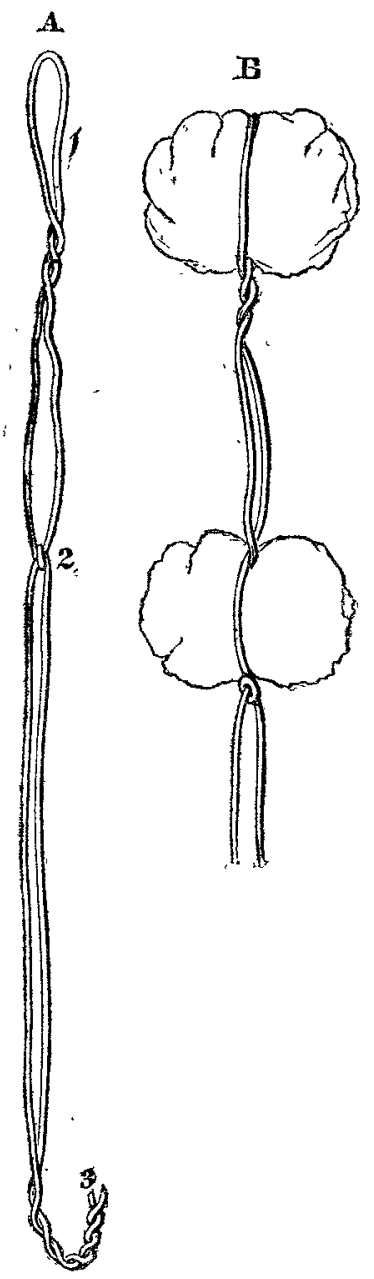

A, Instrument ready for operation-should be about fifteen inches long; $B$, The same after operation, inclosing the posterior pling by torsion, the anterior by knot, the ends cut off at anterior nares; 1 , Duplicature for posterior plug; 2, Noose for anterior plug; 3, Hook to draw the duplicature from pharynx.

Grosvenor-street, Cheltenham, 1849.

ON A

\section{CASE OF DISLOCATION OF THE HUMERUS.}

By H. R. HOSKINS, Esq., Surgeon, Hoxton-town.

I was called in the afternoon of Saturday, the 6th January, to a man who was stated to have injured his arm by a fall. On arriving, I found a man about forty years of age, stout, and muscular. He was sitting with his right arm so much raised that the elbow was very nearly on a level with the top of his head: he complained of great pain and numbness of the whole arm and forearm. The pain was increased by endeavouring to raise the arm still more, and became altogether unbearable on the slightest attempt to depress it, but it could be moved slightly backward and forward withont any great increase of pain. The head of the humerus could be plainly felt in the axilla, and passing over it were two rounded cords, most acutely sensitive to touch or pressure. With the assistance of a friend, I proceeded to reduce the dislocation. Extension was made for this purpose, at first in the only direction in which the arm could be placed, (i. e., very much upward.) When this had been continued a few minutes, I found that the elbow could be brought lower down, and the extension was then continued nearly at a right angle. After a very short interval, I placed my closed hand in the axilla and pressed the head of the bone upward, when it returned to the glenoid cavity with a snap, clearly perceptible both to myself and the patient. There were considerable pain and swelling about the joint, and numbness of the arm; the pain and swelling were quickly subdued, but the numbness, although con. stantly decreasing, still remains to some extent.

The account which I received of the accident, which happened only a few minutes before I was sent for, was, that the man, running out of his house with his arm raised to strike a blow, fell heavily on his back, the posterior part of his shoulder coming in violent contact with a stone, or some other projecting substance, and that he then found his arm fixed in the position I have described.

I have been induced to send this case for publication, believing it to be a very unusual one, as. I cannot remember to have heard or read of anything similar - the remarkable points being the raised position of the arm, and the situation of the nerves on the head of the humerus.

January 23,1849 .

\section{ON THE TREATMENT OF CHOLERA AT LEITH.} WITH A THEORY OF ITS PATHOLOGY.

By ANDREW C. LIVINGSTON, M.D., Leith.

Cholera having prevailed extensively in Leith and its vicinity, and many cases having fallen under my charge, I think it proper, while so many are publishing reminiscences of its former visitation, that those who have had an opportunity of observing the present epidemic should record the fruits of their experience and reflection. I submit the following remarks on its nature and treatment:-

In almost every instance where a favourable result has been obtained, I have found it preceded by profuse sweating, evidently indicating a crisis in the disease, and pointing out the proper object of treatment-viz., the production of a copious diaphoresis. When this could be procured, I invariably found the symptoms to remit, and the patient to fall into a profound slumber, on awakening from which he usually expressed himself much relieved, and by a continuance of the treatment, was eventually cured.

The principal remedies relied on were calomel and opium, in large doses, in men; and onium and camphor, in women; with warm stimulating draughts between the doses, the patient being surrounded wich bottles of hot water, and a sinapism placed over the stomach, taking care not to abandon the treatment hastily, though a few of the first doses might be rejected. By a perseverance in this treatment, the symptoms rapidly alate, and a distinct shivering is frequently observed to precede the crisis of sweating. The only symptom which may prove troublesome, after the more formidable ones have been subdned, is a constant retching. This I found most easily relieved by the use of hydrocyanic acid.

The principal object of this communication, however, is not to recommend any precise treatment, but to indicate some principle upon which treatment ought to be based. All attenupts to treat this disease as having a gastro-enteric location liave been signally unsuccessful, and rest on narrow and fallacious grounds; indeed, a short acquaintance with the present epidemic is sufficient to dispel all such illusion. The matters discharged are not like the evacuations which occur in diarrhceas, and the cramps and subsequent collapse are not in proportion to the matters discharged. In some cases of severe cramps and collapse, little or no vomiting and purging were observed, showing that these symptoms could not have been produced by the exhaustion of the serum of the blood, but were the distinct product of the virus.

If cholera, then, has not a gastro-enteric seat, where ought it to be placed? I have no hesitation in asserting that, it 
ought to be classed with 'he intermittents, and that the group of symptoms usually called cholera do really constitute the cold stage of an intermittent,-no doubt an intermittent having a specific character of its own, but having, at the same time, much in common with other intermittents. Indeed, no one who has had an opportunity of seeing intermittents, even in this country, but must be struck with the remarkable similarity in the physiognomy of the two diseases. The symptoms preceding an attack of cholera-viz., the sudden debility, tremors, general uneasiness, and epigastric oppression, are such as usher in the cold stage of an intermittent; and though the subsequent symptoms are not in all respects similar, yet we lave in both the determination of the fluids to the interior, causing coldness and lividuess of surface, shrunk features, and great prostration; followed, in the one instance, by shivering; in the other, by cramps. The purging and vomiting, which are the result of this determination of fluids to the interior, though not frequent symptoms in the early stage of intermittents, are sometimes, however, observed; while in some of the severer forms of cholera, they are either absent or very limited in amount. But it is not my intention to maintain that there is an absolute identity between cholera and any particular form of intermittent, but that there is such an affinity as to justify this classification, and to point to a more rational mode of treatment. The origin, progress, and present habitudes of this disease, will also tend to confirm this view of its nature. Its first appearance amidst the marshy plains of Bengal; its favourite haunts along the beds of rivers; and its selection of our damp and filthy closes and alleys-which may be regarded as the swamps of our towns, as the principal scene of its ravages,-here cholera will meet with forces acting in the same direction as itself. The malaria of these places, though insufficient of itself to produce the discase, becomes a powerful auxiliary to the cholerific virus; it is of a similar nature, and readily associates with it in action.

This view may tend to dissipate, in some respects, the great obscurity which hangs over the question of contagion. It is well known that intermittents, in certain circumstances, become contagious, and no doubt cholera was so originally, but the cholerific virus, ere reaching this country, has become so weak and attenuated, as to be incapable, of itself, of producing the disease, except in circumstances of peculiar concentration; otherwise it would extend, irrespective of place or person. It is only when it meets with agents which cooperate with it, as in our filthy alleys and swampy places, that it becomes developed, and even then principally in persons of intemperate habits, who are also the chief victims of intermittents in warm countries. It should likewise be remarked, that a lengthened exposure to the miasm is required before the disease can manifest itself. This explains why so few medical men become affected, whose visits are of so short duration; while friends and attendants, who remain longer, are frequently attacked. The only cases where its contagious nature was distinctly exhibited, occurred in individuals who had washed the clothes of cholera patients. Three well-marked instances of this came under my observation, all of whom had cholera in its most virulent form, and died within a few hours. Here the clothes must have im bibed and accumulated the virus direct from the body of the patient, and communicated it, in its most concentrated state, to these persons.

Assuming these views to be correct, the course of treatment becomes obvious. Our whole efforts should be directed to push the disease into its sweating stage, and if called at an early period of the disease, ere collapse shall have occurred, little difficulty will be experienced in arriving at this desirable result. The vomiting and purging-which are the result of internal congestion, and will cease as soon as the skin is stimulated to action-ought in a great measure to be overlooked, and the most powerful sudorifics employed. Those that were found most useful I have already stated, in the earlier part of this communication. The difference of treatment in men and women, however singular, is founded on actual observation. Should cramps be present, anti-spasmodics, such as ether and chloroform, may be used to relieve these, but ought not to be relied on as a means of curing the disease. There is no safety until a warm, copious perspiration shall be produced, and maintained until every vestige of purging and vomiting have ceased. When collapse shall have taken place, this course of treatment becomes less appli. cable, and recourse must be had to the most powerful stimulants. In such cases, consecutive fever usually follows, and must be treated upon general principles.

It is now time that medical men should abandon the em. pirical treatment they have hitherto pursued in cholera, and proceed to investigate, in a more scientific spirit, its true nature, in the trust that it is better to have a principle which connects some of its phenomena, than to be continually groping in the dark.

Leith, 1848.

DESCRIPTION OF $A N$

IRREGULAR DISTRIBUTION OF THE VEINS OF THE NECK.

By HOLMES COOTE, Esq., F.R.C.S.

The following account of an irregularity in the distribution of the vessels of the neck- of importance with reference to the application of a ligature around the subclavian artery, in that part of its course between the outer border of the sterno. mastoid muscle, and the lower border of the first rib,-may be of sufficient interest to merit a place in your journal:-

A well-made, muscular subject, about six feet high, a negro, was received for dissection in the Medical School of St. Bartholomew's Hospital, the last week of December, 1848. The chest was remarkably broad, and the clavicles curved prominently forwards. Upon the reflection of the integuments and the platysma myoides from the right side of the neck, a large vein, an inch and a quarter in diameter, was seen lying immediately to the outer border of the sternomastoid muscle. It received the external and the internal jugular veins, the supra and the posterior scapular veins, and a considerable trunk, which, given off from the cephalic vein, passed over the clavicle, to terminate in this large reservoir. The reflection of the sterno-mastoid muscle brought into view the internal jugular vein, which inclined obliquely outwards, to open into the reservoir in front of the omo-hyoid muscle. The carotid artery and the vagus nerve pursued their usual course, but they were unaccompanied by any vein; the nerve lay external to the artery. The other vessels of the neck presented no irregularity worthy of notice. The distance between the outer border of the sterno-mastoid muscle and the margin of the trapezius measured two inches and a quarter, the clavicles being long. Of this, one inch and a quarter was occupied by the large vein; the remaining inch by the supra-scapular vein and artery, the posterior-scapular vein, the large trunk from the cephalic vein, and the chords forming the axillary plexus of nerves.

It appears to me that, in a neck so constituted, it would be impossible to cut down, with safety to the patient, upon the subclavian artery, as it emerges from between the scaleni muscles. If the irregularity were not observed before the commencement of the operation, the first incision would most probably lay open the large venous trunk, and cause death by the admission of air into the circulation. The application of a ligature to veins of such size would be inadmissible. Southampton-street, Jan. 1849.

\section{TREATMENT OF ULCERS OF THE LOWER EXTREMITY.}

To the Editor of THE LANCET.

SIR,-The admission to the pages of your widely-circulating journal of the accompanying brief remarks upon a notice, in the recent number of the British and Foreign Medico-Chirur. gical Review, of an essay by me on the "Treatment of Ulcers on the Leg, without Confinement, by Bandaging and WaterDressing," will much oblige, your obedient servant,

\section{HenRY T. Chapman, F.R.C.S. \&c.}

The chief practical object of the publication in question is the advocacy of the treatment, not alone of indolent ulcers but of those intractable cases, confirmed irritable ulcers, by a modification of water-dressing and bandaging, in following which $\mathrm{I}$ have met with a greater degree of success than under any other method of treating them.

Applied to the simply indolent ulcer, or to ulcers but slightly irritable, this proceeding differs from the mode of water-dressing employed with the bandage, by many surgeons, in such cases, in the following particular:-After dressing the sore with a compress of wet lint, before the bandage is put on, I encircle the part of the limb on which the ulcer is situated with from three to six, or more, moistened strips of linen or calico, of the same length and breadth as the straps employed by Baynton, drawn tightly, and crossed in precisely the same manner as the adhesive plaster. These wet strips adhere to the skin as closely and smoothly as the strapping; 